\title{
Investigação etnobotânica das plantas medicinais utilizadas para o tratamento de faringoamigdalite no CRAS de Cuité, PB
}

\section{Ethnobotany research of medicinal plants used for the treatment of pharyngitis in CRAS Cuité, PB}

\author{
Monyelle Yvine de Andrade Alencar ${ }^{1}$, Danielly Albuquerque da Costa ${ }^{2}$, Júlia Beatriz Pereira de Souza ${ }^{2}$, Maria Carmem \\ Batista de Alencar ${ }^{3}$ e Egberto Santos Carmo ${ }^{2}$
}

\begin{abstract}
RESUMO - O presente trabalho é um estudo etnobotânico realizado com idosos do CRAS (Centro de Referência de Assistência Social) que investigou o conhecimento popular sobre plantas medicinais para o tratamento de faringoamigdalite no município de Cuité localizado no Curimataú do estado da Paraíba. Essa comunidade mais idosa possui um conhecimento muito grande em relação ao uso de plantas medicinais. Desta forma, o estudo tem por objetivo investigar, documentar e avaliar se há confirmação científica de que a plantas medicinais utilizadas por esta comunidade realmente possuem atividades antimicrobianas. Para esta investigação foi realizada uma pesquisa exploratória, através de entrevistas aplicando-se um questionário semiestruturado com perguntas objetivas e subjetivas, buscando informações sobre o conhecimento da faringoamigdalite e de plantas utilizadas para o tratamento da mesma. A amostra foi composta por trinta idosos. Alguns entrevistados relataram nunca ter utilizado plantas medicinais ou nunca ter apresentado faringoamigdalite, mas os que relataram o uso de plantas medicinais citaram 14 espécies vegetais, consideradas úteis para o tratamento da doença. A principal planta citada por esta comunidade foi a romã (Punica granatum) possuidora de atividade antimicrobiana confirmada cientificamente contra Streptococcus pyogenes umas das bactérias causadora da faringoamigdalite. Os dados obtidos revelam que a comunidade possui conhecimento sobre plantas medicinais com atividade antimicrobiana para tratamento de faringoamigdalite.
\end{abstract}

Palavras-chave: Etnobotânica, Plantas Medicinais, Faringoamigdalite, Streptococcus pyogenes.

\begin{abstract}
The present work is an ethnobotanical study conducted with elderly CRAS (Reference Center for Social Assistance) investigating folk knowledge on medicinal plants for the treatment of pharyngotonsilitis in Cuité city Curimataú located in the state of Paraíba. This elderly community has a great knowledge regarding the use of medicinal plants. Thus, the study aims to investigate, document and assess whether there is scientific confirmation that the medicinal plants used by this community really possess antimicrobial activities. For this investigation was performed an exploratory research through interviews applying a semistructured questionnaire seeking objective and subjective information about the knowledge of pharyngotonsilitis and plants used to treat it. The sample was composed of thirty elderly. Some respondents reported never having used herbal or never had pharyngotonsilitis, but those who reported the use of medicinal plants cited 14 plant species considered useful for the treatment of disease, the main plant cited for this community that is the Pomegranate (Punica granatum) which exhibited antimicrobial activity against Streptococcus pyogenes confirmed scientifically. Data showed that the community has knowledge about medicinal plants with antimicrobial activity for the treatment of pharyngotonsilitis.
\end{abstract}

Keywords: Ethnobotany, Medicinal Plants, Pharyngotonsillitis, Streptococcus pyogenes.

\footnotetext{
*Autor para correspondência

Recebido para publicação em 21/02/2014; aprovado em 12//03/2015

${ }^{1}$ Bacharelado em Farmácia, da Unidade Acadêmica de Saúde, do Centro de Educação e Saúde, Universidade Federal de Campina Grande, campus Cuité/PB.

${ }^{2}$ Doutores e docentes de Bacharelado em Farmácia, da Unidade Acadêmica de Saúde, do Centro de Educação e Saúde, Universidade Federal de Campina

Grande, campus Cuité/PB

${ }^{3}$ Graduada em Enfermagem pela Faculdade Federal de Campina Grande, Especialista em Enfermagem do Trabalho pela FIP.Mestranda em Sistemas

Agroindustriais da UFCG - Pombal
} 


\section{INTRODUÇÃO}

A faringoamigdalite caracteriza-se pela colonização das amígdalas e orofaringe por uma gama de microrganismos que inclui bactérias e vírus. Porém, uma constante preocupação médica são as infecções causadas pelo Streptococcus pyogenes, uma bactéria $\beta$-hemolítica do grupo A de Lancefield, que é potencialmente capaz de causar complicações em órgãos vitais como os rins (VIEIRA et al., 2006; TRABULSI; ALTERTHUM, 2008).

A faringoamigdalite estreptocócica é uma infecção aguda de orofaringe que pode apresentar manifestações sistêmicas, sendo transmitida comumente pelo contato com pessoas infectadas. Esta doença é de grande importância pelo fato de que além de causar complicações supurativas na fase aguda pode causar também sequelas não supurativas mais tardiamente como febre reumática e glomerulonefrite aguda (PITREZ; PITREZ, 2003; SCALABRIN et al., 2003).

Esta infecção ocorre mais frequentemente em crianças e adolescentes na faixa etária de 5 a 15 anos. Ocorre predominantemente em épocas mais frias do ano, principalmente em lugares que há aglomerados de pessoas, como escolas e creches. A passagem de pessoa a pessoa pode favorecer a seleção de cepas bacterianas mais virulentas (SCALABRIN et al., 2003; TRABULSI; ALTERTHUM, 2008).

O diagnóstico dessa doença é realizado através de exame clínico e laboratorial. O diagnóstico clínico baseia-se no conjunto de sinais e sintomas. Os sintomas mais comuns são dor ao deglutir, mal-estar e em crianças, principalmente, esses sintomas podem estar acompanhados de náuseas e vômitos. Os sinais da análise da orofaringe são aumento das amígdalas, presença de exsudato e petéquias no palato (PITREZ; PITREZ, 2003).

O diagnóstico laboratorial consiste, geralmente, na realização da técnica de Gram associada à cultura de secreção de orofaringe. Devido ao tempo que se leva para obter os resultados da cultura os testes rápidos de detecção de antígeno são amplamente utilizados por seus resultados aparecerem em minutos, estes testes têm alta especificidade, mas apresentam uma sensibilidade baixa podendo aparecer resultados falso negativos. O tratamento convencional é a antibioticoterapia, os medicamentos de primeira escolha são a penicilina G e a amoxicilina (PITREZ; PITREZ, 2003; SCALABRIN et al., 2003; MORAIS et al., 2009).

Uma alternativa ao tratamento convencional desta infecção especialmente nos países em desenvolvimento é a utilização de plantas medicinais. Várias plantas apresentaram comprovada atividade antimicrobiana como: Eugenia uniflora (pitanga), Bixa orellana (urucum), Pisidium guajava (goiabeira), Annona muricata (graviola), Persea americana (abacateiro), Punica granatum (romã), Plantago australis (tansagem) entre outras (LORENZZI; MATOS, 2002; GONÇALVES, 2007; OLIVEIRA et al., 2007; FERREIRA; OLIVEIRA; CARDOSO, 2010).

Dentre os que mais frequentemente recorrem ao uso de plantas medicinais para uso próprio ou de familiares estão os idosos, sendo este o grupo onde se obterá um maior conhecimento sobre as plantas utilizadas para faringoamigdalite (MENDONÇA FILHO; MENEZES, 2003).
A etnobotânica está inserida na área da etnobiologia, consistindo em uma ciência que estuda a relação dos seres humanos com as plantas, procurando, cada vez mais, saber como essas plantas são utilizadas pela população e para qual finalidade esse uso se destina. Esses estudos etnobotânicos são de extrema importância para a indústria farmacêutica e saúde, pois podem orientar novas linhas de pesquisas para o estudo farmacológico de novos ativos derivados de plantas (RODRIGUES, 2001)

As plantas medicinais são vegetais que possuem em alguma de suas partes substância que podem ser utilizadas para fins terapêuticos. São utilizadas em todo mundo, decorrentes, geralmente, de uma cultura popular que passa de geração a geração. O Brasil possui uma vasta diversidade cultural e biológica aumentando, assim, cada vez a procura do tratamento de enfermidades através da medicina popular, sendo também alvo de indústrias farmacêuticas em busca de novos medicamentos derivados de plantas com menos efeitos colaterais. Muitas plantas que são usadas popularmente para tratar doenças ainda não foram estudadas cientificamente, nem seus princípios ativos isolados e avaliados, mas várias declarações da população dizem estas serem eficazes e aos poucos as indústrias estão fazendo pesquisas com essas plantas da medicina popular (DUTRA, 2009; ARAÚJO, 2009).

A busca por essa alternativa decorre não somente da eficácia das plantas medicinais, mas, também, de algumas negativas como difícil acesso a medicamentos industrializados devido ao preço e dificuldade de ir ao médico. O uso dessas plantas, apesar de serem naturais, requer cuidado, pois muitas são tóxicas podendo agravar o quadro clínico dos pacientes e, às vezes, conduzir à morte. Toda droga usada como medicamento é potencialmente tóxica, mesmo a planta não sendo considerada tóxica (DUTRA, 2009).

No Brasil os estudos de plantas medicinais com atividade antimicrobiana têm aumentado consideravelmente nos últimos anos, mas esse número ainda é baixo quando se leva em consideração e biodiversidade brasileira. Essa atividade antimicrobiana decorre de componentes presentes nas plantas como: terpenóides, óleos essenciais, alcaloides, lectinas, polipeptídeos, substâncias fenólicas e polifenóis. Alguns estudos tem mostrado sensibilidade de algumas cepas de Streptococcus pyogenes a algumas espécies de plantas, dentre elas o pitangueira (Eugenia uniflora), urucum (Bixa orellana), goiabeira (Pisidium guajava), bálsamo (Myroxilon peruiferum), barbatimão (Stryphnodendron adstringens) (LORENZZI; MATOS, 2002; GONÇALVES; FILHO; MENEZES, 2005; DUARTE, 2006).

Baseado nesta informação teve-se por objetivo investigar quais plantas utilizadas e/ou indicadas por idosos assistidos pelo Centro de Referência de Assistência Social (CRAS) do município de Cuité-PB, para o tratamento de faringoamigdalite.

Este trabalho demonstra sua relevância, primeiro pela contribuição ao estudo etnobotânico das plantas medicinais que são utilizadas e/ou indicadas por idosos do município de Cuité- PB para tratamento de faringoamigdalite, segundo pela verificação da eficácia cientifica destas plantas. 


\section{MATERIAL E MÉTODOS}

O presente trabalho busca a contemplação dos objetivos propostas através de uma pesquisa do tipo exploratória, explicativa e descritiva, com abordagem quantitativa dos dados, que serão dispostos com o uso de valores em porcentagem (POLIT; BECK; HUNGLER, 2004). A pesquisa foi realizada no Centro de Referência de Assistência Social (CRAS) do município de Cuité- PB que é um sistema governamental o responsável pela organização e oferta de serviços da Proteção Social Básica nas áreas de vulnerabilidade e risco social. Por meio do CRAS, as famílias em situação de extrema pobreza, incluídas pelo Plano Brasil Sem Miséria, passam a ter acesso a serviços como cadastramento e acompanhamento em programas de transferência de renda.

O País conta, atualmente, com 7.669 unidades distribuídas pelo território nacional. O principal serviço ofertado pelo CRAS é o Serviço de Proteção e Atendimento Integral à Família (Paif). Dentre os objetivos desse serviço estão a prevenção da ruptura dos vínculos familiares e comunitários, a promoção de ganhos sociais e materiais das famílias e o acesso a benefícios, programas de transferência de renda e serviços socioassistenciais. As ações são todas implementadas por meio de trabalho de assistência social. Além de ofertar serviços e ações de proteção básica, o CRAS possui a função de gestão territorial da rede de assistência social básica, promovendo a organização e a articulação das unidades a ele referenciadas e o gerenciamento dos processos nele envolvidos.

A população foi constituída pelos idosos pertencentes ao CRAS, já a amostra pelos idosos que concordaram em participar da pesquisa através da assinatura do Termo de Consentimento Livre e Esclarecido, sendo ao final 30 participantes, assim foi aplicado um questionário semiestruturado, contendo informações como dados pessoais, nível de instrução, ter utilizado plantas para tratamento de faringoamigdalite entre outros. A pesquisa foi realizada no período diurno, as sextas-feiras em reuniões no CRAS que esses idosos compareciam e através de visitas domiciliares, dando ênfase ao conhecimento popular deles.

A análise estatística ocorreu através da análise dos dados obtidos no questionário, fazendo as proporções adequadas de acordo com a quantidade de entrevistados, que com a utilização do Excel foram dispostos em gráficos ou tabelas, e os dados sobre a confirmação ou exclusão da atividade antimicrobiana das plantas citadas foram obtidas através de pesquisas na literatura cientifica, com base em dados do Scielo, Lilacs e outros.

O estudo desenvolvido foi aprovado pelo Comitê de Ética em pesquisa com seres humanos do Hospital Universitário Alcides Carneiro, com número de protocolo 103.780, conforme Diretrizes e Normas regulamentares de pesquisa envolvendo seres humanos, da Resolução 196/96 do Conselho Nacional de Saúde.

\section{RESULTADOS E DISCUSSÃO}

Foram entrevistadas trinta pessoas com a aplicação do questionário, as entrevistas duraram de dez a quarenta minutos, dependendo do conhecimento, do histórico de ter tido a doença e utilização de plantas medicinais. A maioria dos participantes eram mulheres, sendo a idade média entre homens e mulheres de 66 anos (Figura 01).

Figura 01: Representação do percentual de entrevistado classificado por sexo.

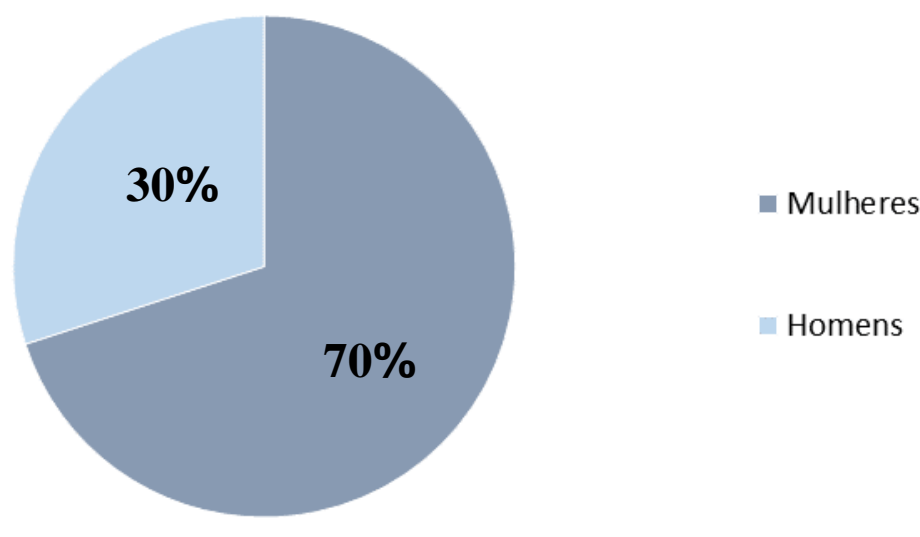

Fonte: Dados da pesquisa. 2015.

Em relação ao estado cívil dos participantes, a maioria dos homens $(77,78 \%)$ eram casados e a maioria das mulheres eram viúvas $(52,38 \%$ ) (Figura 02). Com relação a maternidade, vinte $(95,24 \%)$ das mulheres tinham filhos, assim como todos os homens entrevistados. Dezoito $(85,71 \%)$ mulheres e sete $(77,78 \%)$ dos homens já tinham netos.

Em relação ao grau de escolaridade $19(63,4 \%)$ dos entrevistados, a maioria, possuía o ensino fundamental incompleto, seguido de ensino médio completo, e ensino superior completo (Figura 03).

A profissão dos entrevistados variou muito, mas a maioria dos idosos (16) são aposentados, seguido por agricultores (6) e o restantes das profissões como costureira, dona de casa, secretária, empregada doméstica, advogado, motorista, pensionista e professor foram mencionadas apenas uma vez (Figura 04). 
Figura 02: Gráfico representativo do estado civil dos participantes.

\section{Mulheres}

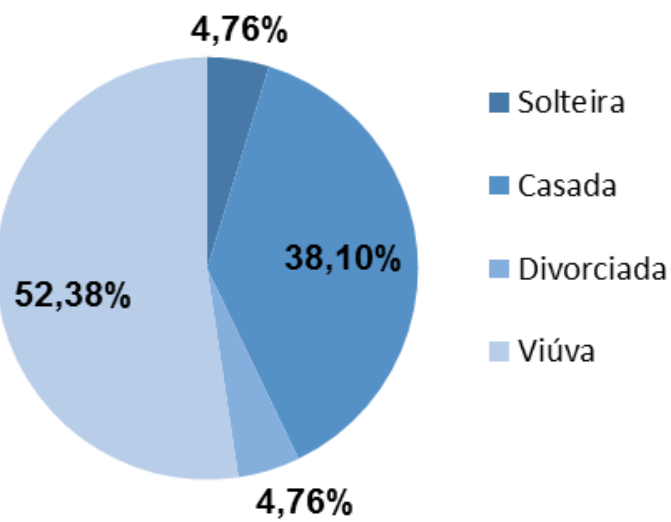

\section{Homens}

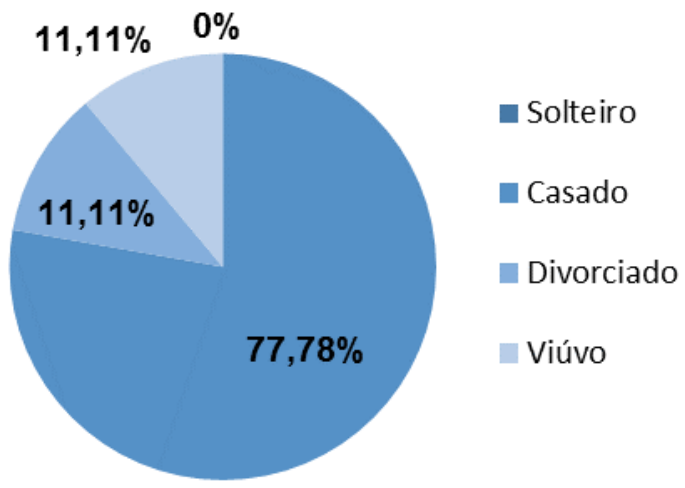

Fonte: Dados da pesquisa. 2015.

Figura 03: Gráfico representativo do grau de escolaridade dos entrevistados.

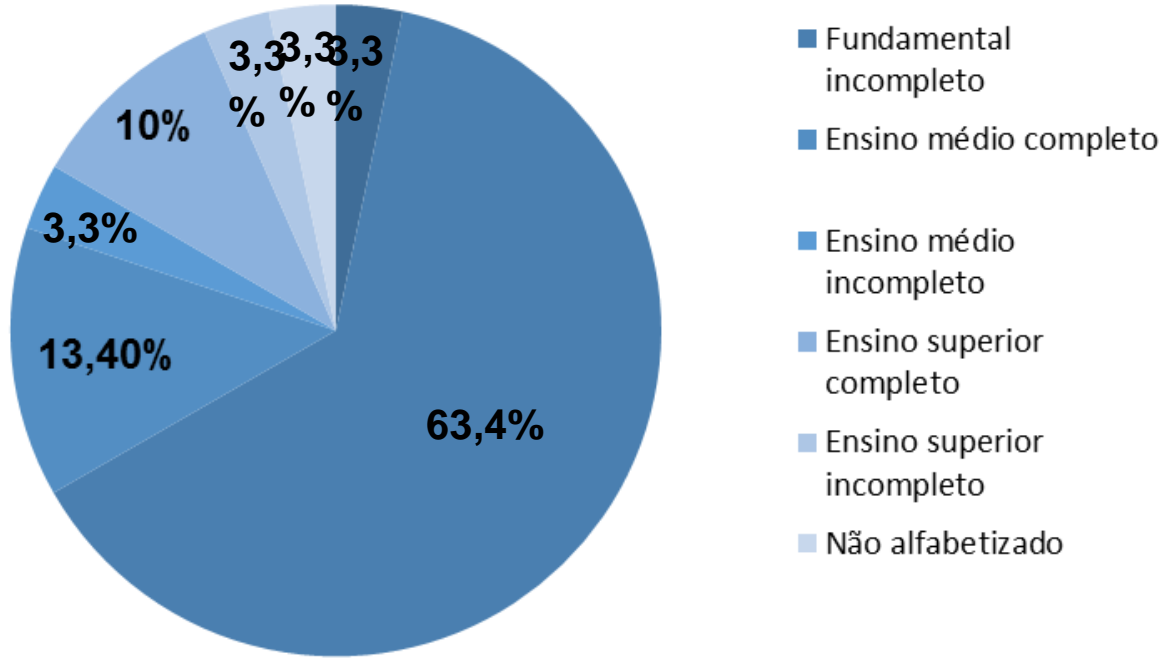

Fonte: Dados da pesquisa. 2015.

Figura 04: Gráfico representativo da profissão dos entrevistados.

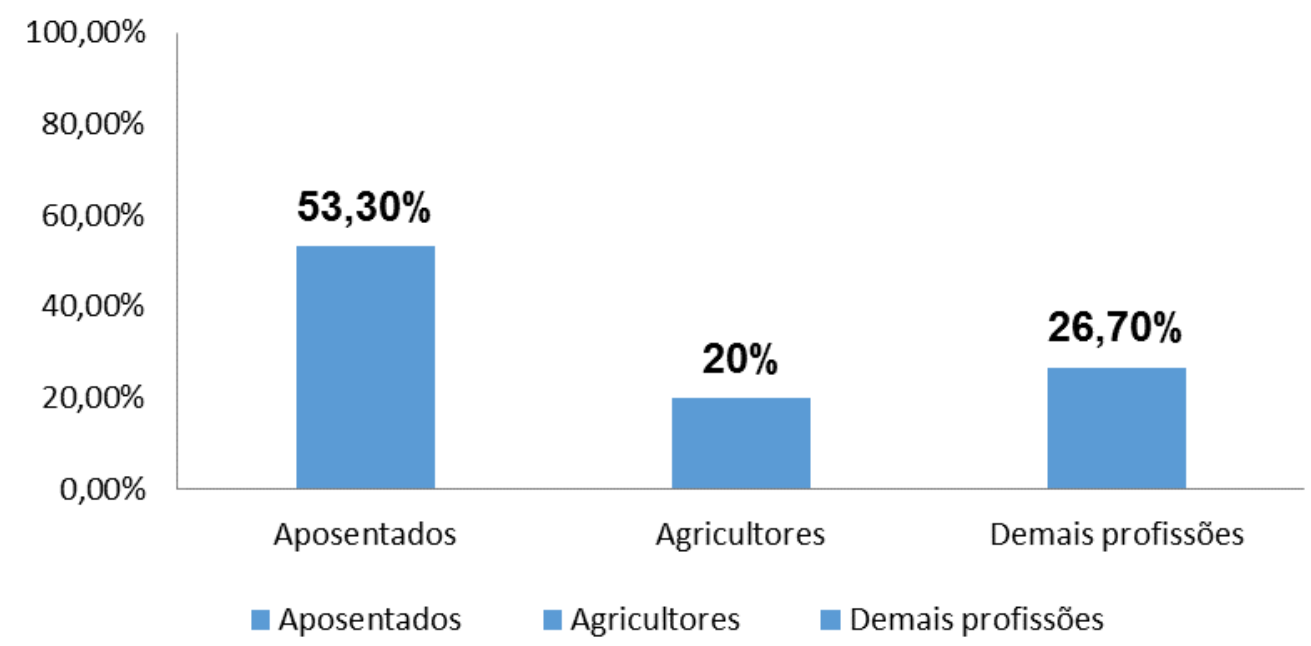

Fonte: Dados da pesquisa. 2015. 
Alguns entrevistados, precisamente oito, relataram nunca ter tido faringoamigdalite. Dois dos entrevistados tiveram a doença, mas nunca utilizaram nenhuma planta medicinal para o tratamento, relatando o uso apenas de medicamentos alopáticos. Vinte entrevistados tiveram a doença e usaram plantas medicinais e/ou indicaram para outras pessoas. Assim, foram registradas 35 citações, onde foram relatadas várias partes das plantas em algumas formas de preparo, estas plantas foram investigadas na literatura e enquadradas em 14 espécies de 13 famílias botânicas. No quadro 1 estão registradas às plantas mencionadas pelos moradores, com os nomes científicos, família botânica, parte da planta utilizada, formas de preparo e indicação (Quadro 01).

Quadro 01: Plantas utilizadas pela população pesquisada

\begin{tabular}{|c|c|c|c|c|c|c|}
\hline $\begin{array}{l}\text { Nome popular/ } \\
\text { Nome científico }\end{array}$ & Família & $\begin{array}{c}\text { Partes } \\
\text { utilizadas: } \\
\text { idosos }\end{array}$ & $\begin{array}{c}\text { Partes } \\
\text { utilizadas: } \\
\text { literatura } \\
\end{array}$ & $\begin{array}{l}\text { Formas de } \\
\text { preparo: } \\
\text { idosos } \\
\end{array}$ & $\begin{array}{c}\text { Formas de preparo: } \\
\text { literatura }\end{array}$ & $\begin{array}{l}\text { Indicação na } \\
\text { literatura }\end{array}$ \\
\hline $\begin{array}{c}\text { Alecrim/ } \\
\text { Rosmarinus } \\
\text { officinalis } L .\end{array}$ & Lamiaceae. & Folhas. & Folhas & Chá. & Chá. & $\begin{array}{c}\text { Antimicrobiana, } \\
\text { digestiva, gases } \\
\text { no aparelho } \\
\text { digestivo, dor de } \\
\text { cabeça. }\end{array}$ \\
\hline $\begin{array}{c}\text { Aroeira/ } \\
\text { Myracrodruon } \\
\text { urundeuva }\end{array}$ & Anacardiaceae & Casca. & $\begin{array}{l}\text { Entrecasca, } \\
\text { brotos e } \\
\text { renovos. }\end{array}$ & Chá. & Chá. & $\begin{array}{c}\text { Antiinflamatória } \\
\text { de afecções em } \\
\text { gengivas e } \\
\text { garganta e } \\
\text { cicatrizante. }\end{array}$ \\
\hline $\begin{array}{c}\text { Capim santo/ } \\
\text { Cymbopogon } \\
\text { citratus }(D C) \text { Stapf. }\end{array}$ & Poaceae & Folhas. & Folhas & Chá. & Chá. & $\begin{array}{l}\text { Antimicrobiana, } \\
\text { calmante e } \\
\text { espasmolítica. }\end{array}$ \\
\hline $\begin{array}{c}\text { Erva cidreira/ } \\
\text { Lippia alba (Mill.) } \\
\text { N. E. Br. }\end{array}$ & Verbenaceae & Folhas. & Folhas & Chá. & Chá. & $\begin{array}{c}\text { Calmante, dor de } \\
\text { cabeça, } \\
\text { espasmolítica. }\end{array}$ \\
\hline $\begin{array}{l}\text { Eucalipto/ } \\
\text { Eucalyptus } \\
\text { globulus }\end{array}$ & Myrtaceae & Folhas. & Folhas & $\begin{array}{l}\text { Chá e } \\
\text { inalação. }\end{array}$ & Chá. & $\begin{array}{l}\text { Antimicrobiano, } \\
\text { antigripal, } \\
\text { congestão nasal. }\end{array}$ \\
\hline $\begin{array}{c}\text { Favela/ } \\
\text { Cnidoscolus } \\
\text { phyllacanthus }\end{array}$ & Euphorbiaceae & $\begin{array}{l}\text { Folhas e } \\
\text { casca. }\end{array}$ & Todas as partes & Chá. & Chá e macerado. & $\begin{array}{l}\text { Antiinflamatório } \\
\text { dermatose, } \\
\text { remoção de } \\
\text { verrugas. }\end{array}$ \\
\hline $\begin{array}{l}\text { Laranja/ Citrus } \\
\text { aurantium } L .\end{array}$ & Rutaceae & Folhas. & $\begin{array}{l}\text { Flores e casca } \\
\text { do fruto e } \\
\text { folhas. }\end{array}$ & Chá. & Chá e macera & $\begin{array}{l}\text { Digestiva, } \\
\text { expectorante, } \\
\text { diurética. }\end{array}$ \\
\hline $\begin{array}{c}\text { Malva rosa/ Malva } \\
\text { sylvestris }\end{array}$ & Malvaceae & Folhas. & $\begin{array}{l}\text { Folhas, flores e } \\
\text { frutos. }\end{array}$ & Chá. & Chá. & $\begin{array}{l}\text { Anti-inflamatória } \\
\text { de afecções da } \\
\text { boca e garganta, } \\
\text { tosse, asma. }\end{array}$ \\
\hline $\begin{array}{c}\text { Mastruz/ } \\
\text { Chenopodium } \\
\text { ambrosioides } L .\end{array}$ & Chenopidiaceae & Folhas. & Folhas. & Chá. & $\begin{array}{l}\text { Sumo e compressa das } \\
\text { folhas. }\end{array}$ & $\begin{array}{l}\text { Estomática, anti- } \\
\text { helmíntica, } \\
\text { bronquite. }\end{array}$ \\
\hline $\begin{array}{c}\text { Pitanga/ Eugenia } \\
\text { uniflora } L\end{array}$ & Myrtaceae & Folhas. & Frutos e folhas. & Chá. & Chá e macerado. & $\begin{array}{l}\text { Antmicrobiano, } \\
\text { antidisentérico, } \\
\text { excitante. }\end{array}$ \\
\hline $\begin{array}{l}\text { Quixabeira/ } \\
\text { Syderoxilon } \\
\text { obtosifolium }\end{array}$ & Sapotaceae & Casca. & $\begin{array}{l}\text { Casca do tronco } \\
\text { e das raízes. }\end{array}$ & Chá & Chá e macerado.. & $\begin{array}{l}\text { Antiinflamatória e } \\
\text { hipoglicemiante. }\end{array}$ \\
\hline $\begin{array}{l}\text { Romã/ Punica } \\
\text { granatum L. }\end{array}$ & Punicaceae & $\begin{array}{l}\text { Casca do } \\
\text { fruto. }\end{array}$ & $\begin{array}{c}\text { Casca do caule, } \\
\text { raiz e fruto, } \\
\text { líquido do arilo } \\
\text { das sementes. }\end{array}$ & $\begin{array}{l}\text { Gargarejo do } \\
\text { macerado e } \\
\text { chá. }\end{array}$ & $\begin{array}{l}\text { Gargarejo ou bochecho } \\
\text { do cozimento da parte. }\end{array}$ & $\begin{array}{c}\text { Faringite, } \\
\text { gengivite, } \\
\text { antidisentérico, } \\
\text { vermes. }\end{array}$ \\
\hline $\begin{array}{c}\text { Sabugueiro/ } \\
\text { Sambucus australis }\end{array}$ & Caprifoliaceae & Casca. & $\begin{array}{c}\text { Flores, } \\
\text { entrecasca e } \\
\text { frutos. }\end{array}$ & Chá. & Chá. & $\begin{array}{l}\text { Anti-inflamatória, } \\
\text { cicatrizante, } \\
\text { diurética, anti- } \\
\text { séptica. }\end{array}$ \\
\hline $\begin{array}{l}\text { Tipi/ Petiveria } \\
\text { alliacea } L .\end{array}$ & Phytolaccaceae & Folhas. & Folhas e raiz. & Chá. & $\begin{array}{c}\text { Chá, gargarejo, } \\
\text { bochecho,cataplasma. }\end{array}$ & $\begin{array}{l}\text { Espasmolítica, } \\
\text { diurética, } \\
\text { sudorífica.. }\end{array}$ \\
\hline
\end{tabular}

Fonte: Dados da pesquisa. 2015. 
As formas de preparo mencionadas pelos entrevistados consistiram em chá que pode ser obtido por infusão ou decocção, além de maceração e inalação. Segundo Silva, Régis e Almeida (2012) a decocção que é o cozimento é indicada para partes vegetais mais duras como raízes, caules e cascas, já a infusão que é o abafamento é utilizada para partes mais moles como flores e folhas. Foram feitas 26 citações sobre formas de preparo, sendo a maioria (17) citações para maceração, gargarejando e bebendo o macerado

A espécie mais citada pelos entrevistados foi a romã recebendo $17(48,57 \%)$ citações, seguida da malva rosa com $4(11,43 \%)$ citações. O tipi, eucalipto e aroeira receberam 2 $(5,72 \%)$ citações, as plantas sabugueiro, quixabeira, alecrim, laranja, favela, erva cidreira, capim santo, mastruz e pitanga foram citada apenas uma vez $(2,85 \%)$.

Investigando na literatura científica se as plantas mencionadas pelos entrevistados apresentavam algum potencial antimicrobiano, alguns trabalhos encontrados comprovam que a maioria das plantas citadas na sua forma inteira ou constituintes químicos presentes tem algum potencial antimicrobiano.

Estudos realizados por Trindade, Fonseca e Juiz (2009) comprovaram a atividade antimicrobiana in vitro que a casca de romã (Punica granatum) possui sobre a bactéria Streptococcus pyogenes e Sthaphylococcus aureus, Pereira et al. (2010) relatam que esta atividade antimicrobiana ocorre devido a presença de fitoconstituintes como alcaloides e taninos. Segundo Silva et al. (2008) em estudos realizados in vitro, o extrato hidroalcoólico do alecrim (Rosmarinus officinalis L.) possui atividade antimicrobiana sobre bactérias orais plactônicas como o Streptococcus mutans.

Os óleos essencias de capim santo (Cymbopogon citratus (DC) Stapf.) e da erva cidreira (Lippia Alba (Mill.) N.E.Br.) possuem atividade antimicrobiana contra algumas bactérias como Escherichia coli. O óleo essencial do eucalipto (Eucalyptus globulus L.) possui atividade bacterioestática contra cepas de Streptococcus mutans, Streptocuccus mitis e Streptococcus salivarus. O extrato hidroalcoólico da aroeira (Myracrodruon urundeuva) e da malva rosa (Malva sylvestris) possuem comprovada atividade antimicrobiana em estudos feitos in vitro em bactérias como Streptococcus mutans e Lactobacillus casei (NOGUEIRA; DIAZ; SAKUMO, 2007; ALVES et al., 2009; ALVES; FREIRES; CASTRO, 2010; VALERIANO et al., 2012).

Bezerra et al. (2012) comprovou que o extrato hidroalcoólico da pitanga (Eugenia uniflora) possui atividade antimicrobiana contra Staphylococcus aureus e Pseudomonas aeruginosa, provavelmente, por causa da presença de fitoconstituintes como taninos, fenóis, flavonóides, alcalóides e saponinas. Estudos realizados por Guedes et al. (2009) mostraram que extrato etanólico $70 \%$ do tipi (Petiveria alliacea L.) possui atividade antimicrobiana contra algumas cepas bacterianas como Streptococcus mutans e Escherichia coli.

Em estudos realizados por Brito, Carvalho e Albuquerque (2007) o extrato do mastruz (Chenopodium ambrósoides L.) não apresentou atividade antimicrobiana contra cepas de Staphylococcus aureus e Escherichia coli. Costa et al. (2010) realizou estudos com a quixabeira (Syderoxilon obtosifolium) verificando uma atividade antimicrobiana sobre cepas de Enterococcus faecalis, mas esta atividade foi considerada baixa.

Não foram encontrados na literatura relatos de estudos in vitro para comprovação da atividade antimicrobiana da favela (Cnidoscolus phyllacanthus), laranja (Citrus auratium L.) e do sabugueiro (Sambucus australis).

Quadro 02: Demonstrativo de espécies associadas a utilização e referências.

\begin{tabular}{|c|c|c|}
\hline Planta & Microrganismo & Referência \\
\hline Alecrim/ Rosmarinus officinalis L. & Streptococcus mutans & SILVA et al., 2008. \\
\hline Aroeira/ Myracrodruon urundeuva & $\begin{array}{c}\text { Streptococcus mutans e Lactobacillus } \\
\text { casei }\end{array}$ & ALVES et al., 2009. \\
\hline $\begin{array}{c}\text { Capim santo/ Cymbopogon citratus }(D C) \\
\text { Stapf. }\end{array}$ & Escherichia coli & VALERIANO et al., 2012 \\
\hline $\begin{array}{l}\text { Erva cidreira/ Lippia alba (Mill.) N. E. } \\
\text { Br. }\end{array}$ & Escherichia coli & NOGUEIRA; DIAZ; SAKUMO, 2007. \\
\hline Eucalipto/ Eucalyptus globulus & $\begin{array}{l}\text { Streptococcus mutans, Streptocuccus } \\
\text { mitis e Streptococcus salivarus }\end{array}$ & ALVES; FREIRES; CASTRO, 2010. \\
\hline Favela/ Cnidoscolus phyllacanthus & Sem comprovação científica & \\
\hline Laranja/ Citrus aurantium L. & Sem comprovação científica & \\
\hline Malva rosa/ Malva sylvestris & $\begin{array}{c}\text { Streptococcus mutans e Lactobacillus } \\
\text { casei }\end{array}$ & ALVES et al., 2009. \\
\hline Mastruz/ Chenopodium ambrosioides L. & $\begin{array}{c}\text { Staphylococcus aureus e Escherichia } \\
\text { coli }\end{array}$ & $\begin{array}{c}\text { BRITO; CARVALHO; } \\
\text { ALBUQUERQUE, } 2007 .\end{array}$ \\
\hline Pitanga/ Eugenia uniflora $L$ & $\begin{array}{c}\text { Staphylococcus aureus e Pseudomonas } \\
\text { aeruginosa }\end{array}$ & BEZERRA et al., 2012. \\
\hline Quixabeira/ Syderoxilon obtosifolium & Enterococcus faecalis & COSTA et al., 2010. \\
\hline Romã/ Punica granatum L. & $\begin{array}{l}\text { Streptococcus pyogenes e } \\
\text { Staphylococcus aureus. }\end{array}$ & TRINDADE; FONSECA; JUIZ, 2009. \\
\hline Sabugueiro/ Sambucus australis & Sem comprovação científica & \\
\hline Tipi/ Petiveria alliacea L. & Streptococcus mutans e Escherichia coli & GUEDES et al., 2009. \\
\hline
\end{tabular}

Fonte: Dados da pesquisa. 2015 
Observou-se que algumas das plantas citadas pelos idosos fazem parte do grupo de plantas de interesse ao SUS como o eucalipto, mastruz, malva rosa e a pitanga. E a maioria das plantas citadas possui atividade atimicrobiana, revelando-se estes possuidores de conhecimento sobre plantas medicinais, porque no presente trabalho a espécie mais citada que foi Punica granatum tem confirmação científica de sua atividade antimicrobiana contra Streptococcus pyogenes e uso para esta enfermidade. Este conhecimento é adquirido principalmente de familiares, tornando-se uma tradição entre as famílias, onde estes conhecimentos medicinais passam de geração para geração.

\section{CONCLUSÃO}

Pode-se observar no presente trabalho que a população idosa assistida pelo CRAS do município de Cuité$\mathrm{PB}$, tem um amplo conhecimento sobre plantas medicinais para tratamento de faringoamigdalite, devido ao fato que a romã a planta mais citada no estudo tem atividade antimicrobiana comprovada cientificamente contra o Streptococcus pyogenes. Esta pesquisa é importante, pois fornece dados para que estudos sejam realizados para a verificação das propriedades farmacológicas e toxicológicas das plantas citadas e se estes vegetais são realmente úteis para a finalidade que se destinam.

\section{REFERÊNCIAS BIBLIOGRÁFICAS}

ALVES, L. A.; FREIRES, I. A.; CASTRO, R. D. Efeito Antibacteriano de Óleos Essenciais sobre Bactérias Formadoras do Biofilme Dentário. Revista Brasileira de Ciências da Saúde, vol. 14, n. 02, p. 57-62, 2010.

ALVES, P. M.; QUEIROZ, L. M. G.; PEREIRA, J. V.; PEREIRA, M. S. V. Atividade antimicrobiana, antiaderente e antifúngica in vitro de plantas medicinais brasileiras sobre microrganismos do biofilme dental e cepas do gênero Candida. Revista da Sociedade Brasileira de Medicina Tropical, vol. 42, n. 02, p. 222-224, mar./abr. 2009.

ARAÚJO, M. M. Estudo Etnobotânico das Plantas Utilizadas como Medicinais no Assentamento Santo Antônio, Cajazeiras, PB, Brasil. Centro de Saúde e Tecnologia Rural, Universidade Federal de Campina Grande. Patos - PB, 2009.

BEZERRA, N. A.; FELISMINO, D. C.; CHAVES, T. P.; ALENCAR, L. C. B.; DANTAS, I. C.; COSTA, L. S. AVALIAÇÃO DA ATIVIDADE ANTIMICROBIANA DE Eugenia uniflora L. Revista de biologia e farmácia, vol. 88 , n. 02, 2012.

BRASIL. Ministério do Desenvolvimento Social. Disponível em: <http://www.brasil.gov.br/sobre/cidadania/brasilsem-miseria/acesso-servicos/centro-de-referencia-deassistencia-social-cras> acesso em 16 de abril de 2013.

BRITO, M. V. H.; CARVALHO, D. S.; ALBUQUERQUE, A. M. M. EFEITO DO EXTRATO DE MASTRUZ EM
CULTURAS DE Staphylococcus aureus E Escherichia coli. Revista Paraense de Medicina, vol. 21, n. 01, jan./mar. 2007.

COSTA, E. M. M. B.; BARBOSAS, A. S.; ARRUDA, T. A.; OLIVEIRA, P. T.; DAMETTO, F. R.; CARVALHO, R. A.; MELO, M. D. Estudo in vitro da ação antimicrobiana de extratos de plantas contra Enterococcus faecalis. Jornal Brasileiro de Patologia e Medicina Laboratorial, vol. 46, n. 03, p. 175-180, junho 2010.

DUARTE, M.C. T. Atividade Antimicrobiana de Planta Medicinais e Aromáticas Utilizadas no Brasil. Centro Pluridisciplinar de Pesquisas Químicas, Biológicas e Agrícolas, DMB - Divisão de Microbiologia. Campinas, 2006.

DUTRA, M. G. Plantas Medicinais, Fitoterápicos e Saúde Pública: um Diagnóstico Situacional em Anápolis, Goiás. Centro Universitário de Anápolis, 2009.

EJZENBERG, B. A conduta frente ao paciente com faringite aguda. Jornal de Pediatria, vol. 81, n. 01, p. 1-2, 2005.

EJZENBERG, B. NASCIMENTO, S. L. GILIO, A. E. LOTUFO, J. P. OKAY,Y. Faringoamigdalites episódicas e recorrentes. Divisão de Pediatria do Hospital Universitário da Universidade de São Paulo, São Paulo, vol. 20, p. 191-210, 1998.

FERREIRA, J. F. OLIVEIRA, P. M. C. CARDOSO, R. R. Atividade antimicrobiana in vitro do extrato aquoso da casca da Punica granatum L. (romã) sobre Streptococcus pyogenes. V Encontro Norte-mineiro de biólogos, 6-10 de outubro, 2010.

GONÇALVES, A. L. FILHO, A. A. MENEZES, H. Estudo Comparativo da Atividade Antimicrobiana de Extratos de Algumas Árvores Nativas. Instituto de Biociências, Departamento de Bioquímica e Microbiologia, São Paulo, vol. 72, n. 03, p. 353-358, 2005.

GONGALVES, A. L. Estudo da atividade antimicrobiana de algumas árvores medicinais nativas com potencial de conservação/ recuperação de florestas tropicais. Instituto de Biociências do Campus de Rio Claro. São Paulo, 2007.

GUEDES, R. C. M.; NOGUEIRA, N. G. P.; ALMEIDA, A. M. F.; SOUZA, C. R. F.; OLIVEIRA, W. P. Atividade Antimicrobiana de Extratos Brutos de Petiveria alliacea L. Latin American Journal of Pharmacy, vol. 28, n. 04, p. 520-524, 2009.

HARVEY, R. A. CHAMPE, P. C. FISHER, B. D. Microbiologia Ilustrada. 3 ed. Porto Alegre: Artmed, p. 79-84, 2008.

LINO, L.M. Factores de virulência em Streptococcus pyogenes. Faculdade de Ciências, Departamento de Biologia Vegetal, Universidade de Lisboa, 2010. 
LORENZI, H.; MATOS, F.J.A. Plantas Medicinais no Brasil: nativas e exóticas. Nova Odessa, SP: Instituto Plantarum, 2002.

MADIGAN, M. T.; MARTINKO, J. M.; PANKEN, J. Microbiologia de Brock. 10 ed. São Paulo: Pretince Hall, pg 70, 2004.

MATOS, F. J. A. Farmácias Vivas. 4 ed. Fortaleza: Editora UFC, 2002.

MATOS, F. S.; REALE, J. A.; NETO, J. S.; BARATA, L.; PAMPONET, L. O.; BRITO, R. M. P. X.; COSTA, V. C. N. B.; VIANA, V. M. S.; CARVALHO, C. M. N. Uso de Antibióticos na Faringoamigdalite Estreptocócica. Gazeta Médica da Bahia, vol. 76, Sup. 03, p. 23-27, 2007.

MENDONÇA FILHO, R. F. W.; MENEZES, F. S. Estudo da utilização de plantas medicinais pela população da Ilha Grande - RJ. Revista Brasileira de Farmacognosia, vol. 13 , p. 55-58, 2003.

MORAIS, S.; TELES, A.; RAMALHEIRA, E.; ROSETA, J. AMIGDALITE ESTREPTOCÓCICA Presunção Clínica versus Diagnóstico. Acta Medica Portuguesa, vol. 22 n. 06, p. 773-778, 2009.

MURRAY, P. R. ROSENTHAL, K. S. PFALlER, M. A. Microbiologia Médica. 6e.d. Rio de Janeiro: Elsevier, 2009.

NOGUEIRA, M. A.; DIAZ, G.; SAKUMO, L. Caracterização química e atividade biológica do óleo essencial de Lippia alba cultivada no Paraná. Revista de Ciências Farmacêutica Básica e Aplicada, vol. 28, n. 03, p. 273 - 278, 2007.

NOSCHANG, J. Variabilidade Genética de Isolados de Streptococcus pyogenes por Meio de Marcadores RAPD. Setor de Ciências Biológicas; Departamento de Patologia Básica, Curitiba, 2006.

OLIVEIRA, F.Q. GOBIRA, B. GUIMARÃES, C. BATISTA, J. BARRETO, M. SOUZA, M. Espécies vegetais indicadas na odontologia. Revista Brasileira de Farmacognosia, vol. 17, Sup. 03, p. 466-476, Jul./Set. 2007.

PELCZAR, M. J. CHAN, E. C. S. KRIEG, N. R. Microbiologia: Conceitos e Aplicações. 2ed, vol 1. São Paulo: Pearson Macron Books, p 101-119, 1997.

PEREIRA, A. V.; PEREIRA, M. C. V.; SILVA, V. A.; AZEÊVEDO, T. K. B.; PEREIRA, M. V.; TREVISAN, L. F. A. Atividade antimicrobiana in vitro do extrato da romã (Punica granatum L.) e alecrim-pimenta (Lippia sidoides CHAM.) sobre plasmídeos de Staphylococcus aureus de origem animal. Revista de Biologia e Farmácia, vol.04, n. 01, 2010.

PEREIRA, B.A.F. Febre Reumática. Sociedade Brasileira de Pediatria, Projeto Diretrizes, 2002.

PITREZ, P. M. C.; PITREZ, J. L. B. Infecções agudas das vias aéreas superiores - diagnóstico e tratamento ambulatorial. Jornal da Pediatria, vol.79, Sup. 01, 2003.

POLIT, D.F; BECK, C. T; HUNGLER, B. P. Análise dos dados de pesquisa. In: Fundamentos de pesquisa em enfermagem: métodos, avaliação e utilização. 5 ed. Porto Alegre: Artmed, 2004.

RANG, H. P. DALE, M. M. RITTER, J. M. FLOWER, R. J. Farmacologia. 6ed. Rio de Janeiro: Elsevier, p. 665$666 ; 2007$.

RENISUS, 2009. Disponível em:< http://portal.saude.gov.br/portal/arquivos/pdf/RENISUS. pdf $>$ acesso em 16 de abril de 2013.

RIVERA, M. Estreptococo Beta Hemolítico do Grupo A (Streptococcus pyogenes). Departamento de Pediatria, Universidad Nacional Autónoma de Honduras. vol. XIX, n. 02, p. 47-50, 1998.

RODRIGUES, J. S. C. Contributo para o Estudo Etnobotânico das Plantas Medicinais e Aromáticas no Parque Natural da Serra de S. Mamede. ICN - PNSSM: Eng. Castro Antunes, FCUL, 2001.

SANTOS, L. F. Manual de Microbiologia Clínica. 3 ed. João Pessoa: Editora Universitária/UFPB, p. 125-130, 2003.

SEVERIANO, M. V. N. DANTAS, I. C. SILVA, J. C. FELISMINO, D. C. Levantamento das Plantas Medicinais Cultivadas no Centro de Estudo e Pesquisa Malaquias da Silva Amorim. Revista de Biologia e Farmácia. vol. 04, n. 01, p. 93-101, 2010.

SILVA, M. S. A.; SILVA, M. A. R.; HIGINO, J. S.; PEREIRA, M. S. V.; CARVALHO, A. A. T. Atividade antimicrobiana e antiaderente in vitro do extrato de Rosmarinus offi cinalis Linn. sobre bactérias orais planctônicas. Revista Brasileira de Farmacognosia, vol. 18, n. 02, p. 236-240, abr./jun. 2008.

SILVA, N. C. B. REGIS, A. C. D. ALMEIDA, M. Z. Estudo Etnobotânico em Comunidade Remanescente de Quilombo em Rio de Contas - Chapada Diamanatina Bahia. Revista Fitos, vol. 07, n. 02, p. 99-109, abril/junho 2012.

SCALABRIN, R.; BUSS, G. D.; IAMAGUCHI, K. C. S.; CARDOSO, C. L.;GARCIA, L. B. Isolamento de Streptococcus pyogenes em indivíduos com 